\title{
Impaired cardiac autonomic nervous control after cardiac bypass surgery for congenital heart disease
}

\author{
Laura McGlone ${ }^{a}{ }^{*}$, Neil Patel ${ }^{b}$, David Youngc, Mark D. Danton ${ }^{\mathrm{b}}$ \\ aPrincess Royal Maternity Hospital, Alexandra Parade, Glasgow, Scotland, UK \\ 'The Royal Hospital for Sick Children, Yorkhill, Glasgow, UK \\ cDepartment of Medical Statistics, University of Strathclyde, Glasgow, UK
}

\begin{abstract}
We undertook a study to describe changes in heart rate variability (HRV) postoperatively in children undergoing cardiac bypass surgery for congenital heart disease (CHD). HRV was recorded for a 1-h period preoperatively and a 24-h period postoperatively in 20 children with CHD. We found a highly significant reduction in HRV in both time and frequency domain indices compared to preoperative values, which was sustained throughout the 24-h study period. There was a negative correlation between both time and frequency domain HRV measurements and length of cardiac bypass. HRV is reduced postoperatively and correlates with cardiac bypass time. Length of cardiac bypass time may be one mechanism whereby HRV is reduced following surgery.
\end{abstract}

Keywords: Cardiopulmonary bypass; Congenital; Autonomic nervous system; Heart rate

\section{Introduction}

Heart rate variability (HRV) is a measure of cardiac autonomic nervous control. In adult patients, reductions in HRV are independent predictors of mortality in congestive heart failure and after myocardial infarction [1-3].

In children with congenital heart disease (CHD), HRV is reduced compared to normal controls and is predictive of sudden cardiac death [1]. Following cardiac surgery for congenital heart disease, HRV is further reduced and may remain reduced years after operation $[2,3]$.

The purpose of this study was to investigate cardiac autonomic function following cardiac bypass surgery for $\mathrm{CHD}$, by recording HRV in the immediate $24 \mathrm{~h}$ period postoperatively, and to compare this to preoperative HRV values. We also wished to assess whether postoperative HVR was affected by length of cardiac bypass.

\section{Methods}

This descriptive cohort study was conducted in the paediatric intensive care unit (PICU) and paediatric cardiology ward of The Royal Hospital for Sick Children, Glasgow. Children were included if they were $<16$ years of age and were to undergo cardiac bypass surgery for CHD. Children were excluded if they had a history of arrhythmias, had a

\footnotetext{
Work presented at: Royal College of Paediatrics and Child Health 11th Spring Meeting April 2007.

Financial Support Department of Cardiac Surgery and Cardiology, The Royal Hospital for Sick Children, Yorkhill, Glasgow.

${ }^{*}$ Corresponding author. Tel.: +441412115388.

E-mail address: mcglonelaura@hotmail.com (L. McGlone).
}

pacemaker, or if they required cardiac pacing postoperatively. Approval was obtained from the Local Ethics Committee prior to study commencement and informed parental consent was obtained for all participants.

\subsection{HRV recording}

HRV was recorded for $1 \mathrm{~h}$ preoperatively (24-48 $\mathrm{h}$ prior to surgery) and for a $24-\mathrm{h}$ period immediately postoperatively on return to PICU.

A 3-channel Holter monitor was used for recording (Pathfinder 700 series, Reynolds Medical Ltd, UK). After skin preparation, electrodes were placed in lead positions 11, $\mathrm{V}_{1}$ and $\mathrm{V}_{5}$. A built-in clock was started after electrode attachment.

\subsection{HRV analysis}

A digital commercial Holter scanner was used to analyse HRV in the time and frequency domain (Pathfinder and HRV Tools ${ }^{\mathrm{TM}}$ software, Reynolds Medical Ltd, UK, on a PC running Windows $2000^{\mathrm{TM}}$ ). Noisy data and artefacts were excluded from analysis. The following time domain parameters were measured from the Holter recording: 1) the sum of all pairs of adjacent $N N$ intervals differing by $>50$ ms (sNN50), 2) the standard deviation of all valid $N N$ intervals in the recording (SDNN), 3) standard deviation of the average of valid NN intervals in 5-min segments in the recording (SDANN), 4) the average of the hourly means of S.D.s of all NN intervals in 5-min segments in the recording (SDNNi) and 5) the average of the hourly square root of the mean 
Table 1

Subject demographics

\begin{tabular}{rcll}
\hline Subject & Age (years) & Diagnosis & Operation \\
\hline 1 & 5 & ASD & ASD repair \\
2 & 6 & TGA, post switch, MR & MV replacement \\
3 & 0.1 & Truncus & Truncus repair \\
4 & 5 & ASD & ASD repair \\
5 & 0.5 & Anomalous LCA & LIMA graft \\
6 & 0.5 & VSD, PFO & VSD, PFO repair \\
7 & 0.4 & AVSD & AVSD repair \\
8 & 16 & Branch PA stenosis & Patch enlargement PAs \\
9 & 4 & DILV, TGA, VSD & TCPC/damus \\
10 & 14 & Sub aortic membrane & Membrane resection \\
11 & 0.5 & AVSD & AVSD repair \\
12 & 1 & VSD/RVOTO & VSD repair/resection RVOTO \\
13 & 5 & Partial AVSD & AVSD repair \\
14 & 0.5 & VSD & VSD repair \\
15 & 0.8 & AP window & AP window repair \\
16 & 5 & TA/VSD/PS & TCPC \\
17 & 5 & PA/AVSD & TCPC/PA reconstruction \\
18 & 5 & TA/VSD & TCPC \\
19 & 15 & TGA/VSD/MR & MV repair \\
20 & 0.5 & VSD & VSD repair \\
& & &
\end{tabular}

ASD, atrial septal defect; TGA, transposition of great arteries; MR, mitral regurgitation; MV, mitral valve; LCA, left coronary artery; LIMA, left internal mammary artery; VSD, ventricular septal defect; PFO, patent foramen ovale; AVSD, atrio-ventricular septal defect; PA, pulmonary artery; DILV, double inlet left ventricle; RVOTO, right ventricular outflow tract obstruction: AP window, aorto-pulmonary window; TA, tricuspid atresia; PS, pulmonary stenosis; TCPC; total cavo-pulmonary connection.

of the sum of the squares of differences between adjacent NN intervals (RMSSD).

Frequency domain analysis was performed using a fast Fourier transform algorithm. An analysis period of $5 \mathrm{~min}$ and a resample rate of $4 \mathrm{~Hz}$ were used. A Hamming windowing function was applied to minimise spectral leakage between segments. Power spectral analysis was reported as high frequency power (HF, range $0.15-0.4 \mathrm{~Hz}$ ), low frequency power (LF, range $0.04-0.15 \mathrm{~Hz}$ ), and total power. The HF:LF ratio was also calculated. All values were calculated preoperatively and at $1 \mathrm{~h}, 6 \mathrm{~h}, 12 \mathrm{~h}, 18 \mathrm{~h}$ and $24 \mathrm{~h}$ postoperatively.

Other data recorded included patient age, diagnosis and operation, cardiac bypass time, cross-clamp time, incidence of cardiac arrest, and mortality.

\subsection{Statistical analysis}

As this was a descriptive study no data were available to inform a power calculation. We recruited the maximum number of patients possible within the 1-year time constraint of the study. Correlations were used to investigate relationships between quantitative variables. Response variables were modelled over time using a general linear model and comparisons were done with pre-op levels using the Bonferroni method for multiple comparisons. All analyses were done using Minitab, version 14, with a significance level of $5 \%$.

\section{Results}

Twenty-seven patients were recruited for the study and results were obtained for 20 (11 males and 9 females). Five patients were excluded because they received external cardiac pacing postoperatively, three for complete heart block and two for sinus bradycardia. Two patients had accidental disconnection of the Holter monitor and insufficient data for analysis. No patients had a tachydysrhythmia postoperatively. The age range was from 1 month to 15 years. Diagnosis and operation undertaken are listed in Table 1.

All cases involved a period of cardiac bypass and 16 cases involved a period of cross-clamping. Length of PICU stay ranged from 1 to 23 days $(4.6 \pm 6.6$, mean \pm S.D. $)$ and hospital stay from 5 to 38 days $(11.5 \pm 8.9)$. All patients had standard intensive care monitoring postoperatively. All patients received analgesia with morphine $20 \mu \mathrm{g} / \mathrm{kg} / \mathrm{h}$ and dopamine $5-10 \mu \mathrm{g} / \mathrm{kg} / \mathrm{min}$ in the immediate postoperative period. There were no episodes of cardiac arrest in the study population and all patients survived to discharge.

\subsection{Time domain HRV}

There were significant reductions in all time domain measures of HRV at all time points postoperatively compared to the pre-op values (Table 2 and Fig. 1), except for the reduction of sNN50 which did not reach statistical significance at $6 \mathrm{~h}(P=0.07)$ and $12 \mathrm{~h}(P=0.059)$. There were negative correlations between all time domain measures of HRV postoperatively and both cardiac bypass time and cross-clamp time (Table 3 ). The negative correlation between SDNNi and cardiac bypass time was statistically significant $(P=0.035)$.

\subsection{Frequency domain $H R V$}

HRV total power, high frequency power and low frequency power was significantly reduced at all time points post-op,

Table 2

Time domain analysis of HRV

\begin{tabular}{|c|c|c|c|c|c|}
\hline \multirow[t]{2}{*}{ Time post-op } & \multicolumn{5}{|c|}{ Time domain index } \\
\hline & sNN50 & $\begin{array}{l}\text { SDNN } \\
(\mathrm{ms})\end{array}$ & $\begin{array}{l}\text { SDANN } \\
(\mathrm{ms})\end{array}$ & $\begin{array}{l}\text { RMSSD } \\
\text { (ms) }\end{array}$ & $\begin{array}{l}\text { SDNNi } \\
(\mathrm{ms})\end{array}$ \\
\hline Pre-op & $80(6-183)$ & $33(25-65)$ & $19(15-44)$ & $15(8-25)$ & $27(13-45)$ \\
\hline $1 \mathrm{~h}$ & $11 *(2-26)$ & $14^{*}(10-18)$ & $11 *(7-15)$ & $5^{*}(3-9)$ & $7^{*}(3-12)$ \\
\hline $6 \mathrm{~h}$ & $27(7-113)$ & $19^{*}(12-27)$ & $16^{*}(9-20)$ & $8^{*}(5-14)$ & $9^{*}(6-18)$ \\
\hline $12 \mathrm{~h}$ & $14(8-32)$ & $15^{*}(8-20)$ & $12^{*}(6-15)$ & $6^{*}(4-17)$ & $8^{*}(5-16)$ \\
\hline $18 \mathrm{~h}$ & $10^{*}(2-25)$ & $14^{*}(12-25)$ & $10^{*}(7-18)$ & $6^{*}(3-11)$ & $10^{*}(6-13)$ \\
\hline $24 \mathrm{~h}$ & $7^{*}(3-21)$ & $22^{*}(12-28)$ & $17^{*}(7-26)$ & $6^{*}(4-11)$ & $10^{*}(6-18)$ \\
\hline
\end{tabular}

Values are median (IQR, Q1-Q3). *Post-op vs. pre-op, $P<0.05$.

HRV, heart rate variability. 


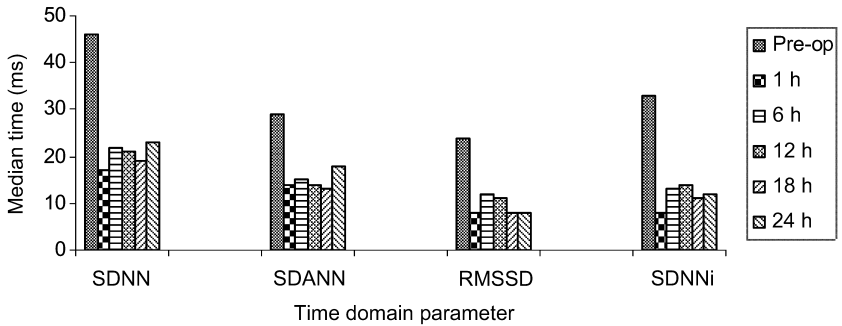

Fig. 1. Time domain measures of HRV pre- and post-op. Significant reduction in SDNN, SDANN, RMSSD and SDNNi at all time points post-op vs. pre-op. $(P<0.05)$.

Table 3

Correlations with time domain HRV

\begin{tabular}{llll}
\hline & Age & Bypass time & Cross-clamp time \\
\hline SNN50 & $0.12(0.56)$ & $-0.28(0.25)$ & $-0.21(0.40)$ \\
SDNN & $0.36(0.13)$ & $-0.36(0.13)$ & $-0.35(0.15)$ \\
SDANN & $0.29(0.23)$ & $-0.28(0.24)$ & $-0.33(0.18)$ \\
RMSSD & $0.29(0.23)$ & $-0.40(0.09)$ & $-0.28(0.25)$ \\
SDNNi & $0.43(0.07)$ & $-0.49(0.04)$ & $-0.39(0.10)$
\end{tabular}

Values are given as correlation, $r$ ( $P$-value).

HRV, heart rate variability.

compared to pre-op (Table 4 and Fig. 2). There was no significant difference between the HF:LF ratio post-op and pre-op. There were negative correlations between all frequency domain measures of HRV postoperatively and both cardiac bypass time and cross-clamp time. The negative correlation between total power and cardiac bypass time was statistically significant $(P=0.048)$ (Table 5$)$.

\section{Discussion}

Markers of autonomic control, including HRV, are a useful predictor of mortality in adult patients with cardiovascular disease and HRV is reduced in children with CHD [1-6].

HRV can be reported by time domain and frequency domain analyses. Time domain indices are derived from simple statistical calculations based on inter-beat intervals. Frequency domain analysis assesses heart rate variance as a function of frequency. The total power spectrum is an expression of overall variability reflecting the combined effects of sympathetic and parasympathetic control of HRV. The power spectra can be subdivided into high and low frequency ranges. HF power represents vagal activity. Controversy exists as to whether LF power represents sympa- thetic control alone or a combination of both sympathetic and parasympathetic control [7-9].

To our knowledge, this is the first study to monitor HRV in the immediate $24 \mathrm{~h}$ post-op and we demonstrate a significant fall in HRV in both time domain and frequency domain parameters. This reduction in HRV was present from $1 \mathrm{~h}$ post-op and sustained for the first $24 \mathrm{~h}$.

These findings of reduced HRV post-op in children with CHD are in accordance with prior studies; Gordon et al. demonstrated reduced frequency domain measures, although no preoperative data were obtained for comparison [5]. Heragu et al. have shown a reduction in time and frequency domain measures of HRV compared to pre-op, but post-op measurements were made on average 5.8 days following surgery, and not in the immediate $24 \mathrm{~h}$ after surgery [9]. Kaltman et al. have also demonstrated a reduction in LF power early after cardiac surgery in newborn infants with single ventricle physiology [10].

The mechanism of this reduction in HRV is unclear. That both LF and HF were reduced post-op, without significant change in the HF:LF ratio suggests that both parasympathetic and sympathetic activity were reduced. This may be due to reduced sensitivity of the sinus node to autonomic nervous input, or alternatively to a central suppression of autonomic stimulation, or a combination of both. Factors which may potentially alter autonomic regulation at this time include the direct effects of surgery [11], the length of cardiac bypass and cross-clamping, and the many pharmaceutical agents used in the peri-operative period. HRV may also be influenced by many additional factors including circulating catecholamines, stress, acid-base status, myocardial ischaemia and reperfusion. Unravelling the confounding effects of these different factors was beyond the scope of this study due to the small numbers studied.

We demonstrated a significant negative correlation between SDNNi and cardiac bypass time, and total power and cardiac bypass time. Length of cardiac bypass time may be one mechanism whereby HRV is reduced in the immediate postoperative period. This is in accordance with Heragu's group who saw greater reductions in time domain parameters in the group of post-op patients with longer bypass times [6]. A criticism of our study is the heterogeneous nature of the population studied, both in terms of age and surgery performed. Future studies should investigate changes in HRV in a more homogenous group and involve comparisons with a control group of children undergoing surgery which does not involve cardiopulmonary

Table 4

Frequency domain indices of heart rate variability

\begin{tabular}{cccc}
\hline & $\begin{array}{l}\text { Total power } \\
\left.\text { (beats } / \mathrm{min}^{2} / \mathrm{Hz}\right)\end{array}$ & $\begin{array}{l}\text { LF power } \\
\left.\text { (beats } / \mathrm{min}^{2} / \mathrm{Hz}\right)\end{array}$ & $\begin{array}{l}\text { HF power } \\
\left(\mathrm{beats} / \mathrm{min}^{2} / \mathrm{Hz}\right)\end{array}$ \\
\hline Pre-op & $345(162-2199)$ & $125(46-592)$ & $21(7-189)$ \\
$1 \mathrm{~h}$ & $20^{*}(5-70)$ & $1^{*}(0-3)$ & $1^{*}(0-2)$ \\
$6 \mathrm{~h}$ & $64^{*}(30-257)$ & $7^{*}(2-52)$ & $3^{*}(1-44)$ \\
$12 \mathrm{~h}$ & $73^{*}(20-282)$ & $10^{*}(2-69)$ & $3^{*}(0-22)$ \\
$18 \mathrm{~h}$ & $109^{*}(36-176)$ & $18^{*}(3-42)$ & $2^{*}(1-21)$ \\
$24 \mathrm{~h}$ & $59^{*}(21-136)$ & $8^{*}(2-25)$ & $0.52^{*}(0.13-2.3)$ \\
\hline
\end{tabular}

Values are median (IQR, Q1-Q3). *Post-op vs. pre-op, $P<0.05$.

HF, high frequency; LF, low frequency. 

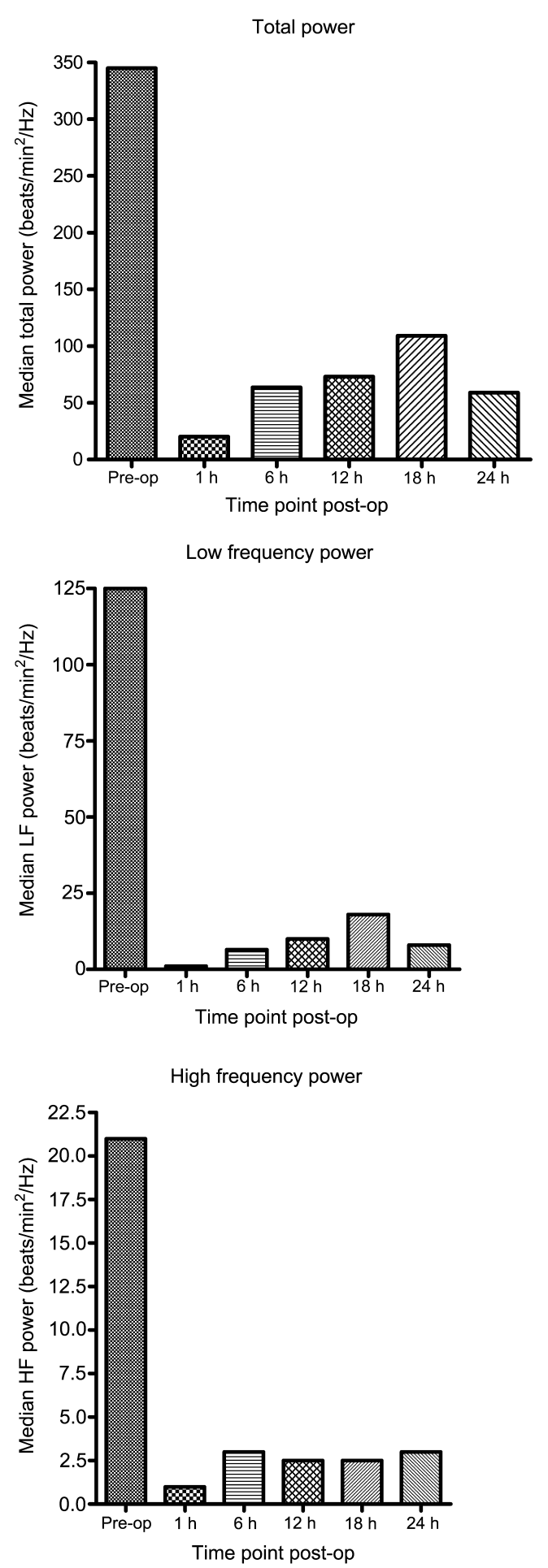

Fig. 2. Frequency domain measures of HRV pre- and post-op. Significant reduction in total, $\mathrm{HF}$ and $\mathrm{LF}$ power at all time points post-op vs. pre-op $(P<0.05)$.

bypass. It was also beyond the scope of this study to investigate the potential underlying mechanisms whereby cardiac bypass time was correlated with HRV, which may include factors such as duration of hypothermia and amount of cardioplegia. Studies involving a larger number of children would be required to further clarify this.
Table 5

Correlations with frequency domain HRV

\begin{tabular}{llll}
\hline Power spectrum & Age & Bypass time & Cross-clamp time \\
\hline Total & $0.35(0.13)$ & $-0.439(0.048)$ & $-0.338(0.15)$ \\
LF & $0.245(0.30)$ & $-0.303(0.19)$ & $-0.267(0.2)$ \\
HF & $0.083(0.73)$ & $-0.293(0.21)$ & $-0.126(0.59)$ \\
HF:LF & $0.283(0.23)$ & $-0.229(0.33)$ & $-0.242(0.30)$ \\
\hline
\end{tabular}

Values are given as correlation, $r$ ( $P$-value).

HRV, heart rate variability; HF, high frequency; LF, low frequency.

\section{Conclusion}

We have demonstrated a highly significant fall in all time and frequency domain measures of HRV in the immediate $24 \mathrm{~h}$ post cardiac bypass surgery in children with $\mathrm{CHD}$. Frequency domain analysis suggests that both sympathetic and parasympathetic cardiac control is affected. There was a significant negative correlation between both time and frequency domain HRV measurements and length of cardiac bypass. Further studies are needed to investigate the mechanisms of changes in HRV and its role as a potential predictor of outcome.

\section{Acknowledgments}

We acknowledge the assistance of David Young with all statistical analysis and the Intensive Care and Paediatric Cardiology Departments at The Royal Hospital for Sick Children, for their support with this study.

\section{References}

[1] Brouwer J, van Veldhuisen DJ, Man in't Veld AJ, Haaksma J, Dijk WA, Visser KR, Boomsma F, Dunselman PH. Prognostic value of heart rate variability during long-term follow-up in patients with mild to moderate heart failure. The Dutch Ibopamine Multicenter Trial Study Group. J Am Coll Cardiol 1996;28:1183-1189.

[2] La Rovere MT, Pinna GD, Maestri R, Mortara A, Capomolla S, Febo O, Ferrari R, Franchini M, Gnemmi M, Opasich C, Riccardi PG, Traversi E, Cobelli $F$. Short-term heart rate variability strongly predicts sudden cardiac death in chronic heart failure patients. Circulation 2003; 107:565-570.

[3] Kleiger RE, Miller JP, Bigger JT Jr, Moss AJ. Decreased heart rate variability and its association with increased mortality after acute myocardial infarction. Am J Cardiol 1987;59:256-262.

[4] Lammers A, Kaemmerer H, Hollweck R, Schneider R, Barthel P, Braun S, Wacker A, Brodherr-Heberlein S, Hauser M, Eicken A, Schmidt G, Hess J. Impaired cardiac autonomic nervous activity predicts sudden cardiac death in patients with operated and unoperated congenital cardiac disease. J Thorac Cardiovasc Surg 2006;132:647-655.

[5] Gordon D, Herrera VL, McAlpine L, Cohen RJ, Akselrod S, Lang P, Norwood WI. Heart-rate spectral analysis: a noninvasive probe of cardiovascular regulation in critically ill children with heart disease. Pediatr Cardiol 1988;9:69-77.

[6] Heragu NP, Scott WA. Heart rate variability in healthy children and in those with congenital heart disease both before and after operation. Am J Cardiol 1999;83:1654-1657.

[7] Davos CH, Davlouros PA, Wensel R, Francis D, Davies LC, Kilner PJ, Coats AJ, Piepoli M, Gatzoulis MA. Global impairment of cardiac autonomic nervous activity late after repair of tetralogy of Fallot. Circulation 2002;106(12 Suppl 1):169-175. 
[8] Akselrod S, Gordon D, Ubel FA, Shannon DC, Berger AC, Cohen RJ. Power spectrum analysis of heart rate fluctuation: a quantitative probe of beat-to-beat cardiovascular control. Science 1981;213:220-222.

[9] Malliani A, Pagani M, Lombardi F, Cerutti S. Cardiovascular neural regulation explored in the frequency domain. Circulation 1991;84:482492.

[10] Heart rate variability. Standards of measurement, physiological inter- pretation, and clinical use. Task Force of the European Society of Cardiology and the North American Society of Pacing and Electrophysiology. Eur Heart J 1996;17:354-381.

[11] Kaltman JR, Hanna BD, Gallagher PR, Gaynor JW, Godinez RI, Tanel RE, Shah MJ, Vetter VL, Rhodes LA. Heart rate variability following neonatal heart surgery for complex congenital heart disease. Pacing Clin Electrophysiol 2006;29:471-478. 
